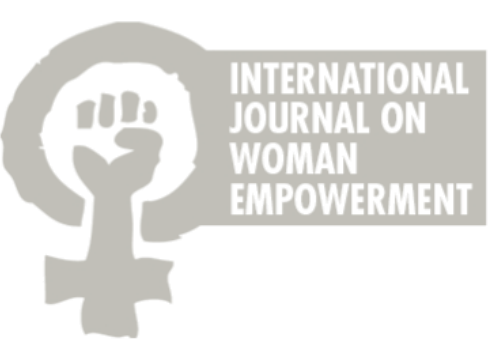

\section{Check for updates}

Copyright (c) The Author(s). 2021 This is an open-access article distributed under the terms of the Creative Commons Attribution 4.0 International License, which permits unrestricted use, distribution, and reproduction in any medium, provided the original author and source are credited.

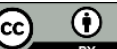

DOI: 10.29052/2413-4252.v7.i1.2021.26-31

Citation: Aftab S, Baloch H, Komal, Saadia, Ghafoor S, Aliya. Maternal and perinatal outcome in adolescent and adult primigravida. IJWE. 2021; 7(1): 26-31

\section{Corresponding Author Email:}

drshaziaaftab@gmail.com

Funding: The author(s) received no specific funding for this work.

Conflicts of Interests: The authors have declared that no competing interests exist.

Received 07/10/2020

Accepted 17/02/2021

First Published 29/06/2021

Original Article

\title{
Maternal and perinatal outcome in adolescent and adult primigravida
}

\author{
Shazia Aftab' ${ }^{1}$ iD, Huma Baloch ${ }^{1}$ (D) , Komal' (D), \\ Saadia Rashid' ${ }^{1}$, Saira Ghafoor ${ }^{2}$ \& Aliya Waheed ${ }^{2}$ iD \\ ${ }^{1}$ Department Obstetrics \& Gynecology, Jinnah Medical College Hospital, \\ Karachi-Pakistan. \\ ${ }^{2}$ Department Obstetrics \& Gynecology, Jinnah Sindh Medical University, Karachi- \\ Pakistan.
}

\section{Abstract}

Background: Improving maternal and child health is prioritized globally; however, adolescent pregnancies remain the prime one among the many obstacles. The study aimed to determine the maternal and perinatal outcomes in adolescent and adult primigravida.

Methodology: This cross-sectional study was carried out between $1^{\text {st }}$ December 2018 to $30^{\text {th }}$ November 2019, over a sample of 487 pregnant women (primigravida), presenting at the Jinnah Medical College Hospital, Karachi, for childbirth/delivery. The patients were categorized as adolescents (aged $\leq 19$ years) and labelled as group A and adults (aged 20-34 years) labelled as group B, comprising 83 and 404 patients. Data were recorded using a structured questionnaire containing details pertaining to socio-demographic characteristics, labour, delivery and immediate postpartum period complications of pregnancy. The data was analyzed using SPSS version 23.0.

Results: A total of 1738 deliveries were completed in the study duration at Jinnah Medical College Hospital, Karachi. The mean age of the women was $18.35 \pm 0.06$ years, and the modal age was 27 years. The mean gestational age of the women was $36.86 \pm 2.15$ weeks among teens and $38.55 \pm 0.55$ weeks among adults. The incidence of adverse outcomes was higher among maternal [anemia; 46.9\% ( $p$-value 0.05)] and perinatal [preterm delivery (20\%), low birth weight (22\%), stillbirth (11.5\%) and perinatal mortality (10\%); $p<0.05$ ] was higher among teens.

Conclusion: It is concluded that teenage pregnancies are comparatively riskier than adult pregnancies for the child and the mother, as is apparent from the significant difference in maternal and perinatal adverse outcomes observed in the study.

\section{Keywords}

Teenage Pregnancy, Adult Primigravida, Maternal Outcome, Perinatal Outcome, Maternal \& Child Health. 


\section{Introduction}

Adolescence, a phase of life wherein crucial developments occur in the structure and function of the body, and the mind prepares a woman for assuming the responsibilities of motherhood ${ }^{1}$. Pregnancy in teenagers (up to 19 years of age) before achieving the prime of adulthood is common worldwide, regardless of social standing, economic level, racial group, or ethnicity. It is, presumably, linked to a heightened chance of poor perinatal and maternal outcomes ${ }^{2}$. As per the statistics put forth by the World Health Organization, an estimated 1,000,000 girls aged below 15 years and another 1,600,000 girls aged 15 to 19 years and 1 million girls aged under 15 years constitute more than a tenth of the global count of child-bearing women global births. A majority of the adolescent child-bearing women hail from low or middle-income countries ${ }^{3,4}$.

Pakistan is a developing country and stands seventh with regards to women achieving childbirth before attaining maturation (i.e., 18 years of age $)^{5}$. Though much improvement has been achieved, with Pakistan having successfully pulled up the average age of marriage from 13.3 years to 23.1 years - over a third are still married prior to attainment of legal age. Consequently, more than a tenth of them bear their first child while being a mean age of just 15 years ${ }^{6}$. It must also be noted that child marriage and teenage pregnancy cases are grossly under-reported, and the real problem may far exceed these figures ${ }^{7}$.

Adolescent pregnancy is generally considered a high-risk group, with research having showcased impacts (stemming from biological immaturity and dietary/nutritional constraints) not only on the emotions, education, and financial situation but the health and wellbeing of the mother, child and the community as a whole ${ }^{1,8}$. While some have contradicted these claims and suggested that the poor outcome may rather be attributed to the concurring in-access to or inability to afford appropriate healthcare ${ }^{\text {? }}$.

In teenagers, complications pertaining to childbirth and pregnancy are the $2^{\text {nd }}$ leading cause of death ${ }^{3}$.
Many studies have found a significant association between teenage pregnancy and adverse perinatal outcomes such as preterm birth, low birth weight, perinatal death and obstructed labor ${ }^{8,9}$. In one study, newborns of teenage mothers have a $50 \%$ risk of low birth weight and perinatal death than those of mothers of 20 to 29 years old ${ }^{3}$. Previous studies have also shown that teenagers are at high risk of fetal growth retardation, fetal distress, use of oxytocin during labour, perineal tears, episiotomy, cesarean delivery and stillbirth².

Encountering stillbirths and perinatal death (within 6 weeks of childbirth) is $50 \%$ more common among teenage mothers than their adult counterparts ${ }^{10}$. Therefore, the present study aimed to evaluate the adverse maternal and perinatal outcomes in adolescent and adult primigravida to improve their management.

\section{Methodology}

This cross-sectional study was conducted from $1^{\text {st }}$ December 2018 to 30 ${ }^{\text {th }}$ November 2019, involving 487 pregnant women (primigravida), presenting at the Jinnah Medical College Hospital, Karachi, for childbirth/delivery. The patients were categorized and placed into two groups, i.e. adolescents (aged $\leq 19$ years) labelled as group $A$ and adults (aged 20-34 years) labelled as group B, comprising 83 and 404 patients. All consenting patients falling within the above-mentioned age ranges were included. While the nulliparous women aged 35 years or above, women with multiple pregnancies, having medical disorders before pregnancy (based on history), and fetal congenital anomalies (diagnosed on ultrasound) were excluded from the study.

The data regarding sociodemographic characteristics, labour, delivery, maternal outcome measures and immediate postpartum period complications of pregnancy were obtained via patient interviews, patient files, labour ward register and hospital maternal health medical records and recorded onto a structured questionnaire. The maternal outcome measures included pregnancy-induced hypertension (BP > 140/90 $\mathrm{mmHg}$ on 2 spontaneous vaginal delivery 
(SVD) and cesarean section and perinatal outcome measured were preterm delivery $(<37$ completed weeks), low birth weight $(\leq 2.5 \mathrm{~kg}$ at any gestational age); Perinatal death (stillbirth and early neonatal death classified as death during the first 7 days of life).

All ethical guidelines were followed and written informed consent was obtained from the participants after explaining the objective of the study. The statistical analysis was done on SPSS version 23.0. Results were expressed as frequencies and percentages, and possible associations were assessed using the chi-square test, where $p$-value < 0.05 was considered significant.

\section{Results}

During the study period of one year, there were a total of 1738 deliveries at Jinnah medical hospital in Karachi. The teenage pregnancies in group A (19 years) were 83 with a prevalence rate of $4.77 \%$, while in group B (20-34 yrs), there were 404 pregnancies with a prevalence rate of $23.24 \%$. The mean age of the women was 18.35 years \pm 0.06 years and ranges 17-19 years, and the values for the control group were $26.9 \pm 3.2$ years. The mean gestational age of the women was $36.86 \pm 2.15$ weeks vs $38.55 \pm 0.55$ weeks in teenagers and adults. The socio-demographic variables, including antenatal profile, educational levels, socioeconomic status, antenatal care and maternal/neonatal outcomes, were studied; inferences are presented in table 1.

Table 1: Baseline characteristics and maternal outcome of the study population.

\begin{tabular}{|c|c|c|c|c|}
\hline \multirow[b]{2}{*}{ Variables } & & \multicolumn{2}{|c|}{ Maternal Age } & \multirow[b]{2}{*}{ p-value } \\
\hline & & $\begin{array}{c}\leq 19 \text { years } \\
(n=83)\end{array}$ & $\begin{array}{c}20-34 \text { years } \\
(n=404)\end{array}$ & \\
\hline \multirow{5}{*}{ Mode of delivery } & Vaginal Delivery & $55(66.26)$ & $190(47)$ & 0.10 \\
\hline & Instrumental Vaginal Delivery & 09(8.1) & $07(6.3)$ & $0.05^{\star}$ \\
\hline & Caesarean Section & 28(33.73) & $214(52.9)$ & 0.10 \\
\hline & $\begin{array}{l}\text { Emergency Lower Segment } \\
\text { Caesarean Section }\end{array}$ & 26(93) & 198(92.5) & 0.13 \\
\hline & $\begin{array}{l}\text { Elective Lower Segment } \\
\text { Caesarean Section }\end{array}$ & $02(7.0)$ & $16(7.5)$ & 0.08 \\
\hline \multirow{4}{*}{$\begin{array}{l}\text { Adverse maternal } \\
\text { outcome }\end{array}$} & None & $41(49.4)$ & $226(56)$ & - \\
\hline & Anemia & $39(46.9)$ & $170(42)$ & $0.05^{\star}$ \\
\hline & Gestational diabetes & $1(1.2)$ & $8(2.0)$ & $0.001^{*}$ \\
\hline & $\begin{array}{l}\text { Pregnancy-induced } \\
\text { hypertension }\end{array}$ & $2(2.5)$ & $27(6.7)$ & $0.01^{*}$ \\
\hline \multirow{2}{*}{ Booking status } & Booked > 4 visits & $48(57.8)$ & $228(56.4)$ & $0.01^{*}$ \\
\hline & Unbooked $<4$ visits & $35(42.2)$ & $176(43.6)$ & 0.10 \\
\hline
\end{tabular}

${ }^{*} p$-value $<0.05$ is considered significant.

The neonatal outcomes among teenage and adult women were significantly different, with neonates borne by teenage mothers encountering poor outcomes in all the below-mentioned regards.

Table 2: Neonatal outcome with respect to maternal age.

\begin{tabular}{lccc}
\hline Neonatal outcome & \multicolumn{2}{c}{ Maternal Age } & p-value \\
\cline { 2 - 3 } & $\begin{array}{c}\mathbf{1} \mathbf{1 9} \text { years } \\
(\mathbf{n}=\mathbf{8 3})\end{array}$ & $\begin{array}{c}\mathbf{2 0 - 3 4} \text { years } \\
(\mathbf{n}=\mathbf{4 0 4 )}\end{array}$ & \\
\hline Preterm & $17(20 \%)$ & $24(6 \%)$ & $0.03^{\star}$ \\
\hline Low birth weight $(<\mathbf{2 , 5 0 0 )}$ & $18(22 \%)$ & $67(17 \%)$ & $0.05^{\star}$ \\
\hline
\end{tabular}




\begin{tabular}{llll}
\hline Stillbirths & $10(11.5 \%)$ & $40(10 \%)$ & $0.02 *$ \\
\hline Perinatal mortality & $8(10.5 \%)$ & $38(9.5 \%)$ & $0.01 *$ \\
\hline${ }^{*}$ p-value $<0.05$ is considered significant. & &
\end{tabular}

\section{Discussion}

Pregnancy and childbirth among women before the attainment of adulthood is a problem faced by women globally ${ }^{5}$. However, the prevalence varies, being as high as $14.3 \%$ in Nigeria and as low as $0.3 \%$ in South Korea ${ }^{1}$. Our research revealed the rate to be $4.77 \%$, which corresponds to Shaikh et al. study from Pakistan wherein the prevalence (just like in most other research from the sub-continent) does not peak above $10 \%{ }^{11}$. Women in the developing world (especially south-east Asia) marry early in their lives. Though the legal age of marriage in most developing countries is set at 18 years, divulgences are common ${ }^{12}$. In this research, the mean age of the women (teenage group) was $18.35 \pm 0.06$ years, reflecting the on-ground scenario at hand ${ }^{11}$.

Pregnancy in the early years of life is rife with problems that are faced by the mother and consequently by the child and society at large. The problems are compounded by the poor socioeconomic condition, the under-developed and under-funded healthcare system leading to many problems ${ }^{13}$. One such issue is anemia. During pregnancy, anemia persists as a pressing problem, with its incidence rates being reported to be rather high $^{14}$. In our research, $46.9 \%$ of the women suffered from anemia, which is synonymous with the statistics yielded by other developing countries ${ }^{5,6,13}$.

The risks of hypertensive disorders vary widely among adolescents; according to studies, some reported increased risk and others decreased ${ }^{14}$ while in our study, the risk was markedly lesser, i.e., $2.5 \%$ as compared to $6.7 \%$ among the younger age group than the adults respectively. This is substantiated by similar results yielded by other studies $^{9,15}$. Maternal gestational diabetes is found to be very lower in our study, i.e., $0.2 \%$ VS $2 \%$ among the young mothers' group, as is supported by matching results in the international literature $\mathrm{e}^{5,714}$.
Adolescent pregnancy is regarded as a hallmark for fetomaternal complications such as low birth weight and prematurity worldwide ${ }^{1}$. In our research, there is a greater risk of low birth weight babies in mothers belonging to younger age group ( $\leq 19$ years), i.e. $22 \%$, which was supported by other studies done by, Johnson et al. ${ }^{16}$ Others reported that young mothers less than 20 years were related to low birth weight ${ }^{5,17}$.

In our study, maternal anemia was the positive finding for low birth weight, which is also seen in various other studies ${ }^{17,18}$. Adolescents were also found to be associated with an increased risk of preterm birth, i.e. $20 \%$ and $6 \%$, which is in keeping with the results of several other studies ${ }^{6,8,11,18}$. In our study, more than $50 \%$ of patients in both groups found were booked, i.e., (57.8\%) and (56.4\%) which is also observed in other studies ${ }^{8,9}$.

The perinatal mortality rate for Pakistan is estimated to be 95 per 1000 births $^{19}$. In our study frequency distribution of stillborn were (11.5\%) and perinatal mortality is (10.5\%), which is much higher than $1.39^{15}$ and $8.6 \%^{1}$ and significantly lower than population-based multi-country research study conducted in south Asian countries ${ }^{9}$. The association of adolescent pregnancy with poor socioeconomic conditions is observed in the developing countries, and also in this study ${ }^{12}$ the reasons may be medical, communal and conventional as well there is lack of general health care facilities in such compromised circumstances prevalent in the developing world ${ }^{5}$.

The study is not without limitations as it is a hospital-based study, and the sample size of our research is small, so limiting the other areas of the community as it may not expose the accurate problems in the community. Further studies are needed for more elaboration of the factors involved in obstetric and perinatal outcomes. 


\section{Conclusion}

In the study, increased risks of maternal and perinatal adverse outcomes identified among adolescent mothers. Adolescent mothers encountered anemia, emergency cesarean section, low birth weight babies and preterm delivery markedly more often than their adult counterparts. As antenatal care directly contributes to adverse maternal and perinatal outcomes thus for better outcomes, young mothers should have proper antenatal follow-up visits and taking proper doses of iron and calcium supplements during the natal and postnatal period. So, to improve outcomes and to decrease complications, the importance of health care facilities and improvement interventions are recommended to optimize birth outcomes.

\section{Acknowledgement}

The technical help and scientific assistance of Dr. Aatir Rajput is acknowledged.

\section{References}

1. Seneesh KV, Shah M. Feto-maternal outcome in teenage pregnancy-a comparative case control study. J Preg Child Health. 2015; 2(136): Article 2.

2. World Health Organization. Discussion Papers on Adolescence: Adolescent Pregnancy. Issues in Adolescent Health and Development. Geneva, World Health Organization, 2004. Available at: http://apps.who.int/iris/bitstream/handle/10665/429 03/9241591455_eng.pdf;jsessionid =7D5855DF03D95 9F85E8E14A07A5B2572? sequence $=1$

3. Tebeu PM, Belinga E, Halle Ekane GE, Mossiang Kadje L, Ekono MR, Mbu Enow R. Teenage pregnancy outcomes in teaching hospitals in yaoundé. Int J Curr Adv Res. 2017; 6(4): 3206-3208.

4. Tsikouras P, Dafopoulos A, Trypsianis G, Vrachnis N, Bouchlariotou S, Liatsikos SA, Dafopoulos K, Maroulis G, Galazios G, Teichmann AT, Von Tempelhoff GF. Pregnancies and their obstetric outcome in two selected age groups of teenage women in Greece. J Matern Fetal Neonatal Med. 2012; 25(9): 1606-1611.

5. Tanveer $Q$, Fatima A. Adolescent pregnancy; a comparative study from the teaching hospital of Lahore, Pakistan. Prof Med J. 2016; 23(6): 727-730.

6. Naz U. Comparison of obstetric outcome in terms of the risk of low birth weight, preterm delivery, cesarean section rate and anemia in primigravid adolescents and older primigravida. J Coll Physicians Surg Pak. 2014; 24(2): 131-134.

7. Ali MM, Rehman MB. Comparison of Maternal and Neonatal Outcomes and Risk factors in Younger and Older Mothers. Ann Community Med Pract 2018;4(2): 1035

8. Jeelani SF, Jangsher S, Saleem BU. Obstetrical outcomes of teenage compared with adult pregnancies. Pakistan J Medical Health Sci. 2017; 11: 416-418.

9. Althabe F, Moore JL, Gibbons L, Berrueta M, Goudar SS, Chomba E, Derman RJ, Patel A, Saleem S, Pasha $O$, Esamai F. Adverse maternal and perinatal outcomes in adolescent pregnancies: The Global Network's Maternal Newborn Health Registry study. Reprod health. 2015;12(2): 1-9.

10. Yussif AS, Lassey A, Ganyaglo GY, Kantelhardt EJ, Kielstein $\mathrm{H}$. The long-term effects of adolescent pregnancies in a community in Northern Ghana on subsequent pregnancies and births of the young mothers. Reprod Health. 2017; 14(1): 1-7.

11. Shaikh F, Abbas S, Sultana F, Yousfani S, Hasan T. Adverse Outcome of a Teenage Pregnancy. J Liaquat Uni Med Health Sci. 2016; 15(04): 179-182.

12. Ali $O E$, Farhan $A E$, Shehata $M$, Ismail MT. Pregnany and Labour Outcome in Teenage. Am J Sci. 2015; 11(10).

13. Anjum A, Manzoor M, Manzoor N, Shakir HA. Prevalence of anemia during pregnancy in district Faisalabad, Pakistan. Punjab Univ J Zool. 2015; 30(1): 15-20.

14. Demirci O, Yılmaz E, Tosun Ö, Kumru P, Arınkan A, Mahmutoğlu D, Selçuk S, Dolgun ZN, Arısoy R, Erdoğdu E, Tarhan N. Effect of young maternal age on obstetric and perinatal outcomes: results from the tertiary center in Turkey. Balkan Med J. 2016; 33(3): 344.

15. Ganchimeg T, Ota E, Morisaki N, Laopaiboon M, Lumbiganon $P$, Zhang J, Yamdamsuren $B$, Temmerman M, Say L, Tunçalp Ö, Vogel JP. Pregnancy and childbirth outcomes among adolescent mothers: a World Health Organization multicountry study. BJOG. 2014; 121: 40-48.

16. Johnson J, Abraham B, Stephenson B, Jehangir HM. Maternal Risk Factors affecting Low Birth Weight babies: A case control study from tertiary care teaching hospital in rural Southern India. IJBRFA. 2016; 7(11): 790-794.

17. Gogoi N. Maternal and Neonatal Risk Factors of Low Birth Weight in Guwahati Metro, Assam, Northeast India: A Cross Sectional Study. Highlights Med Medical Res. 2021;14: 15-22.

18. Azimul SK, Matin A, Shabnam JH, Shamianaz S, Bannerje M. Maternal factors affecting low birth 
weight in urban area of Bangladesh. J Dhaka Med Coll. 2009; 18(1): 64-69.

19. Sami S, Baloch SN. Perinatal mortality rate in relation to gender. J Coll Physicians Surg Pak. 2004; 14(9): 545-548. 